\title{
Identidade étnica na Itália antiga (séculos IV-Ia.C.): fontes, problemas e possibilidades de estudo
}

\author{
Rafael Scopacasa[1]
}

\begin{abstract}
Resumo
Os relatos antigos sobre o início da expansão romana na Itália (séculos V-I a.C.) mencionam vários "grupos étnicos" (ethne; populi) que cruzaram o caminho da república em expansão. No entanto, as narrativas em questão são no mínimo 200 anos posteriores ao período que descrevem. Em que medida os "povos" da Itália pré-romana existiram como tais? O presente artigo aborda essa questão por meio de uma discussão dos diferentes aspectos da identidade étnica, seguindo um eixo temático calcado na teoria antropológica sobre as etnias. Conclui-se que a predominância na historiografia romana de grupos étnicos reflete a condição em que as comunidades italianas interagiram com os romanos entre os séculos IV e III a.C. No entanto, a etnia era um entre vários tipos de identificação coletiva na Itália pré-romana, as quais se encontravam em constante intercâmbio, como identidades cívicas e locais, de classe, familiares, entre outras.

Palavras-chave: identidade étnica; Itália; história romana.
\end{abstract}

\section{Ethnic identity in ancient Italy: sources, questions and possible approaches}

\begin{abstract}
In ancient accounts of Rome's conquest of Italy, various ethne and populi are said to inhabit the peninsula. However, the narratives that convey this information are at least 200 years later than the period that they describe, and rely on sources that are themselves late and complex. To what extent did the Italian "peoples" of the ancient narratives exist as such, and to what degree did Italian communities perceive themselves as ethnically distinct? This paper discusses some key questions, themes and problems concerning ethnicity in ancient Italy in the first millennium BC-with a focus on the last four centuries BC. Although Italian communities occasionally joined together along ethnic lines, such as when dealing with Rome, ethnicity was in fact one of several forms of collective identity that could be activated in ancient Italy, including civic identities as well as class, gender and familial identities.
\end{abstract}

Keywords: ethnicity; Italy; Roman history.

\section{La identidad étnica en la antigua Italia: fuentes, preguntas y posibles enfoques}

\section{Resumen}

Las viejas historias sobre el comienzo de la expansión romana en Italia mencionan varios "grupos étnicos" (ethne; populi) que cruzan el camino de la república en expansión. Sin embargo, las cuentas en cuestión fueron escritas, al menos, 200 años después del período que describen. ¿En qué medida los "pueblos" pre-Romanos de Italia existían como tales? En este artículo se aborda esta cuestión a través de un análisis de los diferentes aspectos de la identidad étnica. Se concluye que la prevalencia en la historiografía romana de grupos étnicos refleja la condición de que las comunidades italianas interactuaron con los romanos entre el tercer y cuarto siglos antes de Cristo. Sin embargo, la etnicidad fue uno de los varios tipos de identificación colectiva en Italia pre-romana, que eran en cambio constante, como la identidad cívica y locales, de clase, familia y otras.

Palabras clave: etnicidad; Italia; historia romana.

\section{L'identité ethnique en Italie antique: sources, questions et approches possibles}

\section{Résumé}

Dans les anciens récits de la conquête romaine de l'Italie, divers ethne et populi italiens sont mentionés. Cependant, les récits qui transmettent ces informations sont été écrits au moins 200 ans plus tard que la période qu'ils décrivent, et reposent sur des sources qui sont eux-mêmes ultérieures et complexes. Dans quelle mesure les «peuples » italiens des récits anciens ont existé en tant que tel, et dans quelle mesure les communautés italiennes ne se perçoivent comme ethniquement distincts? Ce texte traite de quelques questions clés, des thèmes et des problèmes concernant l'ethnicité dans l'Italie ancienne dans le premier millénaire avant JC - avec un accent sur le dernier quatre siècles. Bien que les communautés italiennes à l'occasion réunies comme groupes ethniques, tels que lorsqu'ils traitent avec Rome, l'ethnicité était en fait une de plusieurs formes d'identité collective qui pourraient être activés dans l'Italie ancienne, y compris les identités civiques ainsi que la classe, le et les identités familiales.

Mots-clés: ethicité; Italie; histoire romaine. 
s relatos historiográficos antigos dos primórdios da expansão romana, na Itália, mencionam uma série de povos (ethne nos textos gregos, e gentes ou populi nos latinos) que cruzaram o caminho da república em expansão. Geralmente, os primeiros a aparecer são os latinos e os etruscos, vizinhos mais próximos de Roma, junto com os sabinos, lembrados por sua contribuição ao desenvolvimento inicial de Roma. Em seguida vêm os hérnicos, équos e volscos, logo acompanhados pelos samnitas e lucanos, que controlavam grande parte da Itália centro-meridional e eram uma potência reconhecida. Os vizinhos dos samnitas na Itália central (marsos, marrucinos, pelignos, vestinos e frentanos) também eram famosos por sua disposição guerreira. Já outros povos eram considerados menos belicosos e mais bem dispostos em relação a Roma, como os umbros e os campanos, embora os últimos fossem também vistos como traiçoeiros. No extremo sul, cidades gregas como Taranto e Croton tinham por muito tempo convivido com lucanos, daunos, messápios e iapígios. Ao norte havia os vênetos e os gauleses, e os lígures no litoral tirreno. Os relatos historiográficos transmitem diversas narrativas sobre a origem desses povos, suas características socioculturais e como eles se relacionavam uns com os outros. Os samnitas, por exemplo, eram considerados descendentes dos sabinos, e os lucanos e brútios, dos samnitas. Muitos consideravam os etruscos luxuosos e de origem oriental, enquanto os sabinos eram vistos como austeros e piedosos, características tão valorizadas pela aristocracia republicana romana.

Entretanto, essa imagem da Itália antiga como um "mosaico" de grupos étnicos tem uma série de problemas. Para começar, as narrativas que transmitem essa imagem são pelo menos 200 anos posteriores ao período que elas descrevem e dependem de fontes que eram elas próprias tardias e complexas (Oakley, 1997-2005, v. I, p. 72-99). Os "territórios étnicos" que os autores greco-romanos descrevem fundamentam-se na divisão administrativa da Itália feita durante o reinado de Augusto no primeiro século da era cristã. Além disso, as descrições dos povos itálicos são em grande medida fruto da maneira como os autores gregos e romanos percebiam as comunidades italianas (Dench, 1995, p. 29-32 e 67-68). Temos pouquíssimos textos escritos pelos italianos sobre si próprios antes que todos eles se tornassem cidadãos romanos no século I a.C. Isso tudo gera algumas questões difíceis: Até que ponto os "povos" itálicos das narrativas antigas existiram como tal? Em que medida as comunidades italianas se identificavam como grupos étnicos? Até que ponto o conceito de "etnia" é útil para compreendermos essa fase central da história do Mediterrâneo antigo?

Embora a identidade étnica fosse importante, tratava-se de uma entre várias formas de identidade coletiva, que incluíam também identidades locais, cívicas, socioeconômicas, de gênero, de idade, de profissão etc. No caso dos latinos e etruscos, por exemplo, qualquer sentimento de união étnica teria tido de competir com fortes identidades cívicas que existiam no nível local, uma vez que esses povos eram compostos de cidades-estados independentes, com ideias 
bem desenvolvidas sobre sua própria singularidade (Cornell, 1997, p. 9-10). No que se refere às regiões da Itália onde a urbanização foi menos intensa, especialmente nas porções centrais e montanhosas, tendeu-se a pressupor que a etnia era a única forma realmente importante de identidade coletiva (La Regina, 1981, p. 120-137), embora estudos recentes venham sugerindo o contrário (Scopacasa, no prelo). Por outro lado, é plausível supor que os relatos grecoromanos sobre os ethne itálicos tenham alguma base na realidade, por menor que seja, o que levanta a questão de quais foram os processos históricos que permitiram que esses agrupamentos se formassem (Blake, 2011, p. 204-221).

O presente artigo aborda essa questão por meio de uma discussão dos diferentes aspectos da identidade étnica que as fontes (arqueológicas, epigráficas e literárias, bem como historiográficas) nos permitem estudar, seguindo um eixo temático calcado na teoria antropológica sobre as etnias (autoidentificação, território e fronteiras, cultura, política e memória social). Terminaremos com uma breve discussão sobre o papel da identidade étnica na unificação política da Itália no primeiro século a.C. Conclui-se que a predominância na historiografia romana de grupos étnicos reflete a condição em que as comunidades italianas interagiram com os romanos entre os séculos IV e III a.C. No entanto, apesar de essas comunidades serem capazes de funcionar como grupos étnicos, a etnia era um entre vários tipos de identificação coletiva na Itália pré-romana, as quais se encontravam em constante intercâmbio, como identidades cívicas e locais, de classe, familiares, entre outras - o que já se pode observar desde o período arcaico (século VI a.C.), conforme veremos adiante.

\section{O que é identidade étnica?}

Estudiosos do mundo antigo geralmente seguem a definição antropológica de "grupo étnico" como uma coletividade formada por pessoas que se consideram, e são consideradas, membros do grupo. A inclusão no grupo étnico pode ser feita com base em vários critérios, os principais sendo a crença em uma origem em comum, semelhanças culturais, um senso de história ou passado em comum, e um território em comum, que o grupo pode habitar no momento presente ou projetar no passado distante. ${ }^{2}$ Alguns estudiosos distinguem entre a categorização étnica de pessoas feita por observadores externos (o chamado ponto de vista "ético") e a maneira como indivíduos identificam-se a si próprios (a dita perspectiva "êmica").

Existem diferenças importantes entre o conceito antropológico de grupo étnico, e o que os autores antigos entendem por ethnos ou populus no contexto da Itália pré-romana. O conceito de ethnos era extremamente amplo na Antiguidade, uma vez que podia descrever qualquer grupo de seres com características em comum, incluindo plantas e animais (Morgan, 2003, p. 9-10).

2 Weber (1968, p. 389), Smith (1986, p. 22-30), Eriksen (1993, p. 12) e Altan (1995, p. 19-32). Em relação ao mundo antigo, ver Jones (1997), Hall (1997, 2002 e 2006, p. 40-60), Bradley (2000b, p. 109-129), Dench (1995 e 2005), Farney (2007), Luraghi (2008), Derks e Roymans (2009) e Bourdin (2012). 
No caso de pessoas, o ethnos era tido como um grupo cujos membros tinham uma origem em comum, normalmente de ancestrais míticos, bem como um território em comum, e semelhanças culturais (Hall, 1997; Luraghi, 2008, p. 7). Havia, também, um sentido político mais estreito, em que o ethnos era a união de comunidades que atuavam como uma entidade política maior, que poderíamos chamar de "liga" ou "federação", como era o caso dos tessálios e dos etólios. ${ }^{3}$

Levando-se em conta as diferenças entre os entendimentos antigos e modernos, a definição antropológica de "grupo étnico" pode ser aplicada às coletividades que nossos autores greco-romanos descrevem como ethne, uma vez que há correspondências (Cornell, 1997).

\section{Nomes étnicos}

No final do século II a.C., uma inscrição monumental foi erguida no santuário de Pietrabbondante no Samnium (Itália central). Escrita na língua local (osco), ela era uma das várias inscrições que se referiam às construções monumentais do santuário. O texto é altamente fragmentário, mas um dos trechos sobreviventes parece incluir a expressão safinim sak[araklum], que pode ser traduzida como "o lugar de culto do povo safinim", presumivelmente o próprio santuário de Pietrabbondante. ${ }^{4}$ Do ponto de vista linguístico, é provável que a palavra osca safinim esteja relacionada com o nome Samnites em latim, sendo, portanto, o possível nome que os samnitas davam a si próprios (La Regina, 1981, p. 131-133; Tagliamonte, 1996, p. 8-9).

Graças a inscrições como a de Pietrabbondante, sabemos que os nomes étnicos mencionados nas narrativas greco-romanas ("samnitas", "lucanos", "campanos", "umbros") têm alguma ligação com os nomes que as comunidades italianas davam a si próprias no período pré-romano. Uma pulseira de bronze encontrada na Úmbria exibe uma inscrição com a expressão ombriíen acren, o que é muito provavelmente a versão local do nome étnico "Umbro" (La Regina, 1981, p. 120-137; Bradley, 2000a, p. 24). Mais ao sul, na região da Campânia, a poderosa cidade de Cápua emitiu uma série de moedas no final do século $\mathrm{V}$ a.C. com a legenda kampanos. ${ }^{5}$ Uma série posterior de moedas da Itália meridional, emitidas durante a segunda Guerra Púnica (218-202 a.C.), exibe a palavra loukano $\mu$ (loukanom) no alfabeto grego (Rutter, 2001, p. 129, n. 1.449). Algumas dessas moedas seguem o padrão púnico da época e provavelmente foram emitidas pelos cartagineses como pagamento para seus aliados no sul da Itália (Isayev, 2007, p. 24-25). Como observa Isayev, o nome "loukanom", nesse caso, não se aplicaria a todo o ethnos dos "lucanos" tal como descrito nas fontes greco-romanas, mas apenas às comunidades lucanas que apoiaram

${ }^{3}$ Morgan (2003), Graninger (2011) e Aston (2012, p. 247-271). A ideia do ethnos como uma união de cidadesestados ou poleis já está presente em Aristóteles (Política, 3.5.11); ver Hansen e Nielsen (2004). Contudo, o termo ethnos também era aplicado a poleis individuais, como Atenas; ver Hall (2006, p. 50).

${ }^{4}$ Imagines Pentri, Terventvm 18.

5 Imagines Campania, Capva 1 
Aníbal em vez de Roma. Outra série de moedas do século III a.C., emitida pela cidade de Larino, inclui o termo frentrei (Rutter, 2001, n. 621). Esse pode ser o nome osco dos "frentanos", o ethnos que, de acordo com autores antigos, ${ }^{6}$ ocupava o litoral adriático da Itália central. Da mesma época temos uma tabuinha de bronze proveniente de um santuário em Rapino que faz referência a uma tota marouca. ${ }^{7}$ Esse é provavelmente o nome local do grupo descrito nos textos greco-romanos como o ethnos dos "marrucinos".

\section{As descrições dos povos itálicos são em grande medida fruto da maneira como os autores gregos e romanos percebiam as comunidades italianas}

A inscrição de Rapino é especialmente importante por incluir a palavra itálica tota, que significa "comunidade". A tota marouca seria, portanto, a "comunidade dos marrucinos". O termo também está presente em um conjunto de lápides funerárias da Itália central que contêm a expressão safinas tutas ("comunidade dos safinim"). Seria então a tota o equivalente itálico do conceito grego de ethnos? Não exatamente, já que a palavra tota era usada com referência a tipos muito diferentes de organização social na Itália pré-romana. Enquanto na inscrição Rapino a palavra parece significar um grupo de proporções regionais, e não um assentamento específico, na Campânia o termo era claramente usado com referência a cidades-estados individuais, como Cápua, por exemplo. ${ }^{9}$ Portanto, mesmo que a tota possa ter ocasionalmente assumido características que associamos ao ethnos, tratava-se de um conceito e de uma instituição essencialmente maleáveis.

Os nomes étnicos presentes nas fontes epigráficas provavelmente representam a expressão consciente de identidades étnicas. As inscrições supracitadas parecem comprovar que comunidades italianas deliberadamente se uniram em certos momentos de sua história para formar agrupamentos maiores.

\section{Territórios e fronteiras}

Uma das principais características do grupo étnico é a ideia de um território compartilhado (Hall, 1997, p. 2; Luraghi, 2008, p. 10). Esse pode ser um território ocupado pelo grupo, ou uma pátria ancestral idealizada que é projetada no passado. Embora os grupos étnicos na Grécia antiga não fossem geograficamente coesos, acreditava-se que eles eram originários de regiões específicas, como no caso dos jônios e sua suposta terra natal no norte do Peloponeso (Hall, 1997, p.

\footnotetext{
${ }^{6}$ Estrabão 5.4.2.

7 Imagines Marrucini, Teate Marrvcinorvm 2.

${ }^{8}$ Estrabão 5.4 .2$.

9 Imagines Campania, Capva 24
} 
52). Por outro lado, limites territoriais tendiam a ser mais definidos nos casos em que o grupo étnico agia como uma entidade política, como ocorria com as ligas ou confederações de cidades que se uniam sob um sentimento de identidade étnica compartilhada. Mas mesmo nesses casos as fronteiras mudavam, dependendo de quais cidades estavam incluídas na federação. Por exemplo, listas de vencedores olímpicos nos permitem identificar mudanças na extensão geográfica da federação tessália, à medida que diferentes cidades são mencionadas como membros da liga em diferentes momentos nos séculos III e II a.C. (Graninger, 2011, p. 84). Infelizmente, na Itália não há nenhuma fonte que se assemelhe às listas de vencedores olímpicos da Grécia. Para discutir os territórios e as fronteiras de grupos étnicos no período pré-romano, a maior parte de nossa informação vem de textos literários escritos em períodos bem posteriores, quando a geografia da Itália havia mudado muito em função da unificação política com Roma. Autores como Estrabão e Plínio, o Velho, fornecem relatos detalhados dos vários "povos" que habitaram a Itália, mas em última análise essas descrições remetem à península tal como ela estava organizada no primeiro século da era cristã. Plínio, em especial, fundamentou sua descrição da Itália e seus "povos" nas 11 regiões administrativas criadas durante o governo de Augusto (27 a.C. - AD 14). Cada uma dessas regiões era nomeada a partir de um ou mais povos (por exemplo, Samnium, Lucania et Bruttium, Latium et Campania), mas elas não podem ser consideradas indicadores fiéis dos territórios dos grupos étnicos itálicos, tal como se encontravam organizados no período pré-romano (Isayev, 2007 e no prelo).

Isso não quer dizer que esses grupos étnicos eram desprovidos de qualquer dimensão territorial. Ao contrário, a questão principal é que não eram estáticos, mas sim cambiantes, o que torna difícil, senão inútil, tentar reconstruir fronteiras precisas. Essa mutabilidade das "fronteiras étnicas" encontra-se expressa na historiografia antiga, ainda que indiretamente. Sob uma leitura atenta, fica evidente que autores como Políbio e Lívio não são muito claros sobre onde um ethnos terminava e outro começava. Isso é visível na maneira com que tais autores aplicam o mesmo nome a populações diferentes, em momentos diferentes de suas narrativas. Um bom exemplo diz respeito aos samnitas e dois de seus vizinhos, os frentanos e os hirpinos. Os frentanos ocupavam um trecho do litoral adriático da Itália central, enquanto os hirpinos situavam-se mais a oeste, próximo do litoral tirreno. Ambos os grupos são descritos em nossas fontes como ethne separados. No entanto, Estrabão afirma que frentanos e hirpinos eram samnitas, e Lívio parece incluí-los frequentemente na categoria geral de "samnitas" em sua narrativa. ${ }^{10}$ No que diz respeito aos hirpinos, temos até uma narrativa que descreve sua origem como colonos samnitas liderados por um lobo. ${ }^{11}$ Ao invés de simples inconsistência, esse emprego incongruente de nomes étnicos em Lívio e Estrabão pode ser uma indicação de como as

10 Frentanos: Plínio, História natural, 3.99, 3.105-7, Estrabão 5.4.2; Hirpinos: Estrabão 5.4.12; Plínio, História natural, 3.99, 3.105 .

${ }^{11}$ Estrabão 5.4.12; Festus, p. 93 Lindsay. 
"fronteiras étnicas" na Itália deslocaram-se e reformularam-se ao longo dos últimos quatro séculos a.C. (Isayev, 2007; Scopacasa, no prelo).

Fronteiras étnicas não eram apenas mutáveis. Elas eram também permeáveis, e sua importância dependia do contexto. O período arcaico (séculos VII e VI a.C.) nos oferece exemplos vívidos da permeabilidade de fronteiras étnicas na Itália e de como a identidade étnica poderia ser irrelevante em certos meios sociais. As narrativas sobre Demarato são muito importantes nesse sentido. Em algum momento do século VII a.C., esse aristocrata grego, originário de Corinto, chegou à cidade etrusca de Tarquinii com um grupo de seguidores. Lá ele se casou com uma mulher local e tornou-se pai do homem que, segundo a lenda, viria a fundar a dinastia real dos tarquínios em Roma. ${ }^{12}$ A trajetória de Demarato sugere que, no período arcaico, o Mediterrâneo estava atravessado por redes sociais de longa distância, pelas quais aristocratas podiam circular com certa facilidade. Tais indivíduos teriam sido capazes de ir até onde as oportunidades os levassem (Isayev, no prelo). Quaisquer "fronteiras" étnicas nas regiões abarcadas por essas redes sociais não parecem ter sido fortes o suficiente para deter o movimento de homens como Demarato. ${ }^{13}$

\section{Identidade étnica e cultura}

Por volta de 343 a.C., a cidade de Cápua, na Campânia, decidiu ajudar os sidicinos, um povo vizinho, em sua guerra contra os samnitas. Como resultado, o exército capuano foi duas vezes derrotado em batalha. Quando os samnitas começaram a preparar um ataque à própria Cápua, os capuanos pediram ajuda a Roma. ${ }^{14}$ No texto de Lívio, ao apelar para o senado romano, os embaixadores capuanos descrevem os samnitas como um povo bárbaro e violento, que nada tinha em comum com Cápua ou as outras cidades campanas. Os samnitas são retratados como bandidos sanguinários que não desistiriam antes de se apoderar da riqueza dos capuanos. ${ }^{15}$ A narrativa de Lívio sugere que os capuanos estavam construindo uma retórica que contrastava samnitas "ferozes" com campanos "plácidos", dois grupos com estilos de vida e valores culturais totalmente incompatíveis. Contudo, embora seja perfeitamente plausível que samnitas e campanos estivessem enfatizando suas diferenças ao se confrontarem em 343 a.C., as evidências arqueológicas e epigráficas mostram que comunidades tanto no Samnium como na Campânia (incluindo Cápua) compartilhavam uma série de características culturais à época em questão, como já havia sido o caso por vários séculos. Todos eles falavam a língua osca e escreviam no alfabeto osco, cunhavam moedas segundo os mesmos padrões de peso e valor, e contavam com estruturas e instituições políticas compatíveis,

\footnotetext{
12 Sobre as diferentes versões da história de Demarato, ver Políbio 6.11.6-7; Lívio 1.34-35; Dionísio de Halicarnasso, Antiguidades romanas, 3.46-49; Estrabão 5.2.2; Plínio, História natural, 35.43.152.

${ }^{13}$ Isayev (no prelo), Cornell (1995, p. 163-165), Lomas (2000, p. 88) e Ampolo (1976-1977, p. 333-345) (o último discute evidências epigráficas de mobilidade aristocrática atravessando divisões políticas e étnicas no Lácio e na Etrúria durante o século VI a.C.).

${ }^{14}$ Lívio 7.29-30; ver Oakley (1997-2005, v. II, p. 285-286).

${ }^{15}$ Lívio 7.30.1-7.
} 
como a tota e o magistrado meddiss (La Regina, 1981, p. 120-137). Suas atitudes culturais referentes à morte e ao sepultamento também eram bastante semelhantes, como a preferência pelo rito da inumação, com o corpo enterrado em posição supina em sepulturas individuais (Scopacasa, no prelo). Estavam todos familiarizados com as formas ritualizadas de beber vinho que chamamos de "versão etrusca" do simpósio clássico, e tendiam a adorar os mesmos deuses, como Júpiter, Héracles e Mefitis (Scopacasa, no prelo). No entanto, apesar dessas semelhanças socioculturais, os capuanos (e, presumivelmente, outros campanos) eram capazes de ver-se como radicalmente diferentes dos samnitas em 343 a.C.

\section{O período arcaico nos oferece exemplos vívidos da permeabilidade de fronteiras étnicas na Itália e de como a identidade étnica poderia ser irrelevante em certos meios sociais}

O episódio narrado ilustra a relação complexa que existe entre identidade étnica e cultura. Por um lado, semelhanças culturais sustentam a construção da identidade étnica, na medida em que tais semelhanças oferecem uma base para que o sentimento de pertença e solidariedade possa se cristalizar entre as pessoas (Smith, 1986, p. 22-30; Altan, 1995, p. 19-32). No entanto, as características culturais específicas, com as quais os grupos étnicos se identificam, variam muito de um caso para outro. ${ }^{16}$ A mera existência de semelhanças culturais entre as pessoas não cria, automaticamente, um sentimento de afinidade e identidade (Bentley, 1987, p. 24-55). Por outro lado, certos grupos étnicos podem parecer culturalmente heterogêneos para um observador externo, mas ainda assim seus membros podem se considerar semelhantes. $\mathrm{O}$ antropólogo norueguês Fredrik Barth usou vários exemplos etnográficos para demonstrar que a percepção que as pessoas têm de sua identidade étnica frequentemente tem pouco a ver com semelhanças ou diferenças culturais "objetivas" entre essas mesmas pessoas. ${ }^{17}$ Em outras palavras, o que importa não é se semelhanças culturais existem, mas se essas semelhanças são consideradas relevantes pelo próprio grupo étnico.

No que diz respeito ao mundo antigo, as fontes nos dão alguma informação sobre quais características culturais poderiam ser consideradas indicativas de identidade étnica. O exemplo mais conhecido é o trecho de Heródoto no qual o "ser grego" (hellenikon) é definido em vista de uma língua em comum e de cultos religiosos em comum. ${ }^{18}$ Consequentemente, muita atenção tem sido dada ao papel da língua e da religião na construção da identidade étnica no mundo

${ }^{16}$ Ver, por exemplo, Patterson (1975, p. 306)

17 Barth (1969, p. 14); ver também Smith (1986, p. 27), Eriksen (1993, p. 12) e Jones (1997, p. 126).

${ }^{18}$ Heródoto 8.144; sobre as diferentes leituras desse trecho, ver Raaflaub (2002, p. 167). 
antigo. ${ }^{19}$ Em relação à Itália, já está claro que o culto em santuários era um meio importantíssimo de autodefinição coletiva, assim como na Grécia. O exemplo mais evidente é o festival de Júpiter Latiaris, realizado no monte Albano, onde, a cada ano, as cidades latinas reafirmavam os laços étnicos que as uniam, participando dos cultos e sacrifícios comunais e recebendo suas devidas porções da carne sacrificial (Cornell, 1997). No entanto, nenhuma das características culturais que constituíam o culto religioso nesses festivais - como as divindades veneradas, os artefatos oferecidos como ex-votos e os modelos arquitetônicos utilizados na construção de templos — era exclusiva de determinados grupos étnicos. Ao contrário, os vestígios arqueológicos mostram que práticas religiosas na Itália antiga eram marcadas por tendências culturais de amplo alcance geográfico. As mesmas divindades, como Júpiter e Héracles, eram adoradas por toda a península; ex-votos de barro, em forma de órgãos e membros do corpo, eram extremamente comuns entre os séculos IV e II a.C. (Glinister, 2006, p. 10-33). Do século III a.C. em diante, a maior parte do centro e do sul da península assistiu à construção de templos monumentais que seguiam as últimas modas do mundo helenístico (Wallace-Hadrill, 2008, p. 99; Scopacasa, 2014, p. 69-87). Todas essas tendências culturais atravessavam "fronteiras" entre os vários grupos étnicos que se desenvolveram na Itália durante esse período - o que nos leva à difícil questão do estudo da identidade étnica a partir de vestígios arqueológicos.

\section{Identidade étnica e cultura material}

Por muito tempo acreditou-se que os vestígios materiais da Itália pré-romana "refletiam" os grupos étnicos mencionados nos relatos de Lívio, Estrabão e Plínio, o Velho. ${ }^{20}$ Entretanto, ao contrário de suposições que dominaram a arqueologia por boa parte do século $\mathrm{XX}$, sabe-se agora que vestígios materiais não oferecem um "registro fóssil" de grupos étnicos do passado (Jones, 1997, p. 106-110). Na ausência de fontes escritas, é muito difícil identificar grupos étnicos no registro arqueológico - visto que a identificação étnica não depende da mera existência de semelhanças culturais, conforme vimos, mas sim de como essas semelhanças culturais são percebidas pelo próprio grupo étnico. Tal constatação levou alguns estudiosos a adotar posições extremas. Por exemplo, de acordo com Jonathan Hall (2002, p. 24), “[...] não pode haver uma arqueologia da identidade étnica entre as sociedades que não nos deixaram fontes [escritas]".

Embora seja arriscado estudar a identidade étnica com base em vestígios de cultura material, não se trata de uma tarefa impossível. A arqueóloga Sian Jones (1997) oferece uma saída para o dilema ao propor que a identidade étnica, embora subjetiva e situacional, é fundamentada na prática social das pessoas em sua vida cotidiana. Baseando-se no conceito de habitus de Pierre Bourdieu

\footnotetext{
19 Stek (2009, p. 51-52) (sobre a Itália central).

20 Para uma discussão sobre esse problema e abordagens alternativas, ver Bradley (2000b, p. 109-129).
} 
(1977), Jones sugere um "caminho do meio" para resolver o problema, propondo que as evidências arqueológicas nos permitem reconstruir o habitus de sociedades passadas - ou seja, os estilos de vida, valores e disposições culturais de sociedades antigas que teriam servido de base para a construção de identidades coletivas. Outros estudiosos partem da premissa de que a cultura material desempenha um papel crucial na forma como as pessoas exprimem conscientemente sua própria identidade étnica. Indivíduos podem sinalizar sua etnicidade por meio de certos tipos de roupas, ou certos tipos de recipientes associados a hábitos alimentares que são próprios de determinada cultura (Shennan, 1994).

É em vista desse problema que Emma Blake (2011, p. 204-221) defende aquilo que ela denomina uma abordagem "interacionista" ao estudo da identidade étnica por meio da arqueologia. Sua premissa é a de que o grupo étnico se fundamenta em conexões ou redes sociais, por meio das quais os membros do grupo se comunicam e interagem. Ela propõe que é possível identificar as redes sociais que sustentam grupos étnicos pelo exame dos vestígios materiais da comunicação entre os membros do grupo (Blake, 2011, p. 205). Blake demonstra sua abordagem com um estudo de caso referente às regiões da Etrúria e do Lácio na Idade do Bronze, onde teriam existido duas redes sociais regionalmente definidas, que ela chama de "protoetrusca" e "protolatina". Essas teriam sido redes de pessoas cuja interação social era próxima e constante o suficiente para sustentar, posteriormente, a formação das etnias etrusca e latina no primeiro milênio a.C.

\section{Lingua}

Em algum momento do século III ou II a.C., o poeta Ênio afirmou que ele tinha "três corações" (tria corda), porque falava grego, osco e latim. ${ }^{21}$ A constatação de Ênio chama nossa atenção para o fato de que a língua podia ser um importante símbolo de identidade étnica na Itália antiga, pelo menos em certas ocasiões. Um bom exemplo remete-nos novamente ao santuário samnita de Pietrabbondante. No final do século II a.C., esse santuário estava sendo denominado o "santuário dos samnitas (safinim)", o que sugere que ele se tornara um foco de resistência samnita a Roma nos anos tensos que antecederam a Guerra Social de 91 a.C. (La Regina, 1976, p. 219-244; Stek, 2009, p. 51-52). Possivelmente, o uso da língua osca em todas as inscrições públicas nesse santuário pode ter sido parte de um programa ideológico, no qual o osco funcionava como símbolo de identidade samnita em contraposição a Roma (latim). É significativo que a única inscrição em latim até agora recuperada em Pietrabbondante foi feita em uma telha de cobertura - que evidentemente não estava destinada à exibição pública (Adams, 2003, p. 125; Scopacasa, no prelo).

No entanto, embora a língua pudesse ser usada para sinalizar diferenças étnicas em determinados contextos, ela não era um marcador étnico em si

${ }^{21}$ Aulus Gellius 17.17.1. 
mesma (Hall, 1997, p. 180). Há, na verdade, poucos indícios de que as pessoas na Itália antiga associavam língua e identidade étnica. As poucas fontes que temos sobre essa questão dizem respeito, sobretudo, a Roma e ao Lácio, e mesmo nesses casos parece que a língua era associada principalmente a identidades locais ou cívicas, ao invés de étnicas. Graças às comédias de Plauto (séculos III-II a.C.), sabemos que as cidades latinas estavam bem conscientes das diferenças entre seus dialetos locais, ao ponto de essas diferenças poderem ser usadas para efeito cômico. O exemplo mais claro é o caso do latim falado na cidade de Praeneste, o qual, nas peças de Plauto, é apresentado como risível e inferior ao latim de Roma. ${ }^{22}$

\section{Estereótipos culturais}

Embora saibamos que os grupos étnicos da Itália pré-romana não eram blocos homogêneos com características culturais claramente definidas, certos estereótipos culturais ficaram associados a alguns desses povos na literatura greco-romana. A partir do século III a.C., os sabinos eram geralmente vistos como dignos e piedosos (Dench, 1995, p. 85-94; Farney, 2007, p. 97-112), enquanto os samnitas eram frequentemente colocados no papel de bárbaros agressivos e irascíveis (Dench, 1995, p. 98-103; Scopacasa, no prelo). O amor ao luxo, que era associado aos etruscos, levou muitos a acreditar que eles tinham origens orientais (Keyser, 2011, p. 48). O estereótipo do "luxo decadente" também ficou associado aos campanos e umbros, sendo os últimos também considerados um povo extremamente antigo (Bradley, 2000a, p. 20-22). Olhando de perto, vemos que muitas dessas imagens não eram tão unilaterais. Os samnitas podiam, às vezes, ser vistos sob uma luz mais positiva, como aliados austeros e confiáveis dos romanos, ao passo que nem mesmo o sabinos estavam completamente livres do estigma de "bárbaro opulento" (Dench, 1995, p. 87-90).

Em alguns casos, as fontes arqueológicas parecem explicar por que certos estereótipos ficaram associados a certos povos. Por exemplo, o fato de as comunidades na região do Samnium tenderem a investir mais recursos em edificações públicas do que privadas provavelmente ajudou a gerar o estereótipo dos samnitas como um povo austero (Dench, 1995, p. 130-153). Mas, ao invés de um processo pelo qual autores gregos e romanos simplesmente projetavam seus preconceitos sobre italianos "passivos", os próprios italianos se envolveram ativamente com as visões de seus observadores, ressignificado-as de acordo com suas necessidades, seus interesses e seu repertório cultural. ${ }^{23}$ Aristocratas da região do Sabinum, por exemplo, ativamente manipularam os aspectos positivos de sua identidade étnica tal como ela era percebida pelos romanos, enfatizando sua piedade e austeridade em imagens e textos que eram incluídos nas moedas que esses aristocratas cunhavam. ${ }^{24} \mathrm{O}$ caso dos

22 Plautus, Truc., 687; ver Dench (1995, p. 74).

${ }^{23}$ Ver Farney (2007, p. 33) (sobre como os grupos étnicos respondem ativamente às percepções de "outros").

${ }^{24}$ Ver Farney (2007, p. 80-88) (para uma discussão aprofundada das fontes numismáticas). 
sabinos mostra como a identidade étnica era uma ferramenta para o lobby político entre aristocratas italianos recém-integrados à cidadania romana nos séculos III e II a.C. Isso, por sua vez, nos leva à questão de como a identidade étnica tende a estar estreitamente associada à política.

\section{A língua podia ser um importante símbolo de identidade étnica na Itália antiga, pelo menos em certas ocasiões}

\section{Identidade étnica e política}

"É a política que define a identidade étnica, e não o contrário" (Derks e Roymans, 2009, p. 1-2). No mundo grego, a identidade étnica era frequentemente utilizada como um meio de consolidar a união política de comunidades no que poderíamos chamar de "federações" ou "ligas" (Morgan, 2000, p. 189-211, e 2003; Graninger, 2011). O mesmo vale para a Itália antiga (Herring e Lomas, 2000). Muitos dos grupos étnicos italianos funcionavam como organizações políticas. De fato, os autores antigos viam os ethne italianos como formações políticas, muito como as cidades-estados, a principal diferença sendo no tamanho. É muito significativo, por exemplo, que Lívio utilize a mesma palavra (fines) para se referir às fronteiras de cidades-estados como Roma ${ }^{25} \mathrm{e}$ a grupos étnicos como os samnitas. ${ }^{26}$ Isso é consistente com o fato de Diodoro Sículo afirmar que o grupo étnico (ethnos) dos campanos foi "montado" (sunístemi) em um ano específico (438 a.C.). ${ }^{27} \mathrm{O}$ fraseado de Diodoro e a referência a uma data pontual sugerem que o autor estava pensando em um evento político no qual os líderes das comunidades da Campânia se reuniram para negociar uma união.

Havia muitas razões pelas quais ligas ou "federações" étnicas eram formadas. Uma delas era a necessidade de regular disputas e conflitos entre comunidades em determinada região. Estados se uniam para defender-se de inimigos em comum, ou para lançar-se em empreitadas imperialistas. Visto que a maioria das fontes nos dão o ponto de vista romano, sabemos muito pouco sobre a dinâmica e as interações que ocorriam dentro das ligas étnicas da Itália. Há, no entanto, algumas exceções, como as breves referências que Lívio faz aos assuntos internos da Liga Latina. Como mencionado, as cidades latinas celebravam sua identidade étnica compartilhada no festival anual de Júpiter Latiaris no monte Albano, onde cada cidade recebia sua porção de carne sacrificial. ${ }^{28} \mathrm{O}$ senso de comunidade étnica entre as cidades latinas chegou a ser forte o sufi-

\footnotetext{
25 Lívio 1.11.1.

${ }^{26}$ Lívio 8.2.8; ver também Dionísio de Halicarnasso, Antiguidades romanas, 15.10; Bourdin (2012, p. 459).

27 Diodoro Sículo 12.31.1.

${ }^{28}$ Dionísio de Halicarnasso, Antiguidades romanas, 3.57, 8.18, 9.1; ver também Cornell (1997).
} 
ciente para que elas agissem de forma coesa em momentos decisivos, como quando a liga declarou guerra contra Roma em 340 a.C. ${ }^{29}$

Contudo, ligas étnicas nem sempre funcionavam da maneira como deveriam. No mundo grego, os membros das ligas étnicas muitas vezes brigavam entre si em vez de colaborar, por causa de rivalidades internas e disputas por status. Às vezes, os Estados mais poderosos tentavam usar a liga como um meio de promover suas próprias agendas imperialistas, gerando dissidência dentro do grupo (Buckler e Beck, 2008, p. 12-23). De fato, diplomacia e política externa teriam sido assuntos muito mais complexos em ligas étnicas que em poleis individuais (Aston, 2012, p. 263). Coisas semelhantes aconteceram na Itália, tal como nos é sugerido por breves referências em Lívio a episódios de tensão dentro da Liga Latina. Em duas ocasiões, no início do século II a.C., Lívio observa que o festival de Júpiter no monte Albano teve de ser comemorado duas vezes no mesmo ano, porque certas cidades reclamaram que não tinham recebido sua porção devida da carne sacrificial. ${ }^{30}$ Às vezes, as tensões dentro das ligas aumentavam até o ponto em que os Estados que as compunham tomavam medidas diferentes em relação à guerra e à política externa. Por exemplo, Lívio relata que em 318 a.C., no meio de uma grande guerra entre Roma e a liga samnita, várias "comunidades samnitas" tentaram negociar um tratado de paz. Pode ser que os membros da liga não estivessem inteiramente de acordo quanto ao que deveria ser feito àquela altura, e que algumas comunidades romperam com a união e tomaram a iniciativa diplomática por conta própria. Essa imagem de dissidência interna é consistente com o registro arqueológico do Samnium no século IV a.C. A fortificação de diversos assentamentos durante esse período sugere que havia certo grau de hostilidade entre assentamentos vizinhos, levando-os a proteger-se uns dos outros, e também a afirmar seu poderio por meio de muralhas e torres imponentes. ${ }^{31}$ Por outro lado, o ethnos dos samnitas era provavelmente muito mais coeso, estável e bem-sucedido do que qualquer união política possa ter sido tentada entre as cidades etruscas, por exemplo. Sabemos que havia 12 cidades etruscas que se uniram para formar uma liga, a qual se reunia periodicamente no santuário de Voltumna, perto de Volsinii. ${ }^{32}$ No entanto, essas comunidades nunca funcionaram como uma entidade política coesa. ${ }^{33}$

As fontes epigráficas sugerem que identidades étnicas provavelmente tiveram de "competir" com identidades locais ou cívicas, não apenas nas regiões mais urbanizadas, como a Etrúria e o Lácio. Inscrições contendo nomes étnicos parecem formar uma minoria quando comparadas às referências a identidades locais, vinculadas a determinadas cidades e assentamentos. Nas moedas, em especial, referências a cidades são muito mais frequentes do que referências

${ }^{31}$ Ver Bispham, Bradley, Hawthorne e Kane (2000, p. 23-24) (sobre o centro fortificado de monte Pallano no Samnium, Itália central).

${ }^{32}$ Ver, por exemplo, Lívio 4.23

${ }^{33}$ Eckstein (2006, p. 123); Lívio (4.23.4-24.2) narra um episódio em que as 12 cidades etruscas quase foram para a guerra conjuntamente. 
a grupos étnicos. ${ }^{34}$ Mas isso não significa que identidades locais ou cívicas eram mais importantes do que identidades étnicas. As referências a cidades individuais podem simplesmente ser devidas à necessidade de nomear a autoridade política responsável pela emissão do dinheiro, e não que as pessoas valorizavam sua identidade cívica mais do que sua pertença étnica. Dito isso, a forte ênfase em identidades cívicas presente nas fontes epigráficas nos ajuda a ver como os autores antigos usam categorias étnicas de uma maneira extremamente generalizante, encobrindo uma pluralidade de comunidades locais e independentes.

\section{Origens e memória}

A crença em origens em comum é um elemento definidor do grupo étnico. Isso significa que a construção da identidade étnica depende diretamente da elaboração de ideias sobre o passado - algo que os sociólogos chamam de memória coletiva (Assman, 2011). A memória coletiva que sustenta a identidade étnica geralmente envolve a elaboração do dito "parentesco fictício", ou seja, laços de parentesco que unem os membros do grupo étnico, vinculando-os a supostos antepassados em comum. No mundo grego, esse tipo de parentesco fictício era expresso na forma de genealogias míticas, como o "Catálogo das Mulheres”, atribuído a Hesíodo (Hall, 1997, p. 42-44). O parentesco fictício também poderia existir como um sentimento mais difuso de ascendência compartilhada (Malkin, 2001, p. 10-12).

Estudos sobre o mundo grego vêm explorando magistralmente como a expressão da identidade étnica estava intimamente associada à construção de memória coletiva. Um ótimo exemplo é o trabalho de Nino Luraghi (2008) sobre os messênios. Luraghi sustenta que a identidade étnica messênia foi construída no século IV a.C., quando o Estado de Messene foi criado no oeste do Peloponeso, após a derrota espartana de 369 a.C., que eliminou a dominação lacedemônia da região. Os membros do novo Estado identificaram-se como "messênios", que haviam retornado do exílio em que seus antepassados tinham sido supostamente lançados séculos antes por causa da conquista espartana que teria ocorrido no século VII a.C. Como argumenta Luraghi, o objetivo principal dessa história era gerar um sentimento de herança compartilhada entre os membros do Estado recém-criado e ao mesmo tempo legitimar suas reivindicações à terra, em virtude de sua suposta descendência dos habitantes originais da região (Luraghi, 2008, p. 25 e 105-106).

$\mathrm{Na}$ Itália, o vínculo entre identidade étnica e memória coletiva era rico e complexo como na Grécia, mas a falta de fontes escritas antes do século II a.C. torna muito difícil abordar essa questão a fundo. Compreensivelmente, a atenção dos estudiosos tem se centrado na Roma tardo-republicana, o contexto mais bem documentado. Há muitos estudos sobre como os relatos sobre as

${ }_{34}$ Ver Lomas (2000, p. 88), Yntema (2009, p. 145-166) (sudeste da Itália), Scopacasa (no prelo), Isayev (2007) (Lucânia) e Bradley (2000a) (Úmbria). 
origens de Roma produzidos nesse período serviram como mitos de fundação para a Itália unificada da era de Augusto (Dench, 1995, p. 80-107). Um aspecto importante desses relatos é a afirmação de que Roma nasceu de uma união multiétnica, incluindo latinos, sabinos e etruscos. ${ }^{35}$ Essa ideia de identidade étnica mista foi fundamental na construção da própria identidade romana: após a concessão de cidadania romana aos italianos, em 90 a.C., tornou-se necessário construir uma imagem de união "primordial" entre Roma e a Itália, postulando vínculos de consanguinidade entre latinos, etruscos e romanos. ${ }^{36}$

\section{As fontes epigráficas sugerem que identidades étnicas provavelmente tiveram de "competir" com identidades locais ou cívicas}

É mais difícil, mas não impossível, examinar como as outras comunidades italianas - além de Roma - fizeram uso do passado a fim de fundamentar, manter ou transformar suas identidades étnicas. As fontes greco-romanas às vezes nos dão vislumbres desse fenômeno. Lívio, por exemplo, refere-se a um episódio que teria ocorrido no século III a.C., no meio de uma grande guerra entre Roma e os samnitas: no episódio em questão, os samnitas se reúnem para realizar um ritual antigo, com o objetivo de formar uma legião de soldados de elite que deveria derrotar os romanos de uma vez por todas. De acordo com o sacerdote que liderou os procedimentos, esse ritual era extraído da "velha religião dos samnitas". Aqui temos um exemplo, ainda que indireto, de como certas comunidades italianas recorriam a ideias sobre um passado em comum como forma de articular um senso de identidade, interesses e objetivos compartilhados. A importância da memória, nessa ocasião, é ainda indicada pelo fato de que, de acordo com Lívio, o ritual executado pelos guerreiros samnitas era o mesmo que seus ancestrais haviam realizado décadas antes ao conquistarem a cidade de Cápua na Campânia. ${ }^{37}$ Não é de surpreender que esses exemplos se refiram a situações de conflito: geralmente, é em momentos de estresse que as comunidades se sentem compelidas a traçar distinções mais rígidas entre os que estão "dentro" e os que estão "fora".

\section{Genealogias étnicas}

Havia vários mitos que tratavam das origens e das relações entre os povos da Itália. Um conjunto desses mitos é conhecido como as narrativas das "primaveras

\footnotetext{
${ }^{35}$ Farney (2007, p. 3) e Dench (1995, p. 93-117). Esse cenário multiétnico provavelmente existiu de fato no período arcaico; ver Ampolo (1976-1977, p. 333-345) e Isayev (no prelo).

${ }^{36}$ Ver, por exemplo, Florus 2.6.1-7; cf. Farney (2007, p. 4-5); ver também Cícero, Balb., 31, Tácito, Anais, 11.23-4; Dench (2005, p. 21-25 e 93-151) e Scopacasa (2007, p. 33-39).

${ }^{37}$ Lívio 10.38.6. No relato liviano, o sacerdote que conduz a cerimônia refere-se à conquista de Capua pelos samnitas, que supostamente ocorreu em 423 a.C. (ver Lívio 4.37.1-3).
} 
sagradas" ${ }^{38}$ A versão mais conhecida conta como os samnitas eram os descendentes de colonos sabinos que se viram forçados a migrar em busca de uma nova pátria. A história começa com o sabinos desejando aliviar o sofrimento que resultava de uma longa guerra contra os umbros. Para ganhar o favor divino, o sabinos decidem dedicar ao deus Ares todas as crianças que haviam nascido na primavera do ano em questão. ${ }^{39}$ Ao atingir a idade adulta, esses indivíduos sagrados deixam sua terra natal, partindo em busca de um novo lar, sob a liderança de um animal sagrado, no caso um touro.

Uma narrativa bastante semelhante fala de como os picentes também descendiam de imigrantes sabinos. Nesse caso, o animal guia era um pica-pau (picus, em latim), que teria dado o nome à etnia. ${ }^{40}$ Também os paelignos eram tidos como originários dos sabinos. ${ }^{41}$ Em outras versões da "primavera sagrada", os samnitas são eles próprios os progenitores de outros povos itálicos, como os lucanos e os mamertinos.

É importante ressaltar que as narrativas da "primavera sagrada" permitiam diferentes leituras. Por um lado, essas genealogias míticas integravam povos individuais em "famílias" étnicas maiores; mas ao mesmo tempo essas narrativas descreviam o processo pelo qual esses mesmos povos tornaram-se distintos uns dos outros. Como afirma Dench, as narrativas das primaveras sagradas poderiam ter sido usadas para enfatizar ora a proximidade entre os povos itálicos, ora a distância que os separava. Esses eram mitos flexíveis que permitiram interpretações contrastantes, o que significa que provavelmente foram utilizados para sustentar diferentes discursos de identidade (Dench, 1995, p. 199). Essa própria ambiguidade aponta para o dinamismo com que as pessoas na antiga Itália eram capazes de articular sua pertença a diferentes tipos de coletividade.

\section{Conclusão: Roma e a "identidade italiana"}

A visão que os romanos tinham das comunidades italianas foi determinada pelas forças militares que eles encontraram conforme se expandiram pela península (Bradley, 2000a, p. 117). Isso explica a predominância, na historiografia romana, de representações das comunidades italianas como grupos étnicos unificados e coesos, uma vez que essa teria sido a condição em que essas comunidades interagiram com os romanos entre os séculos IV e III a.C. No entanto, o fato de essas comunidades serem capazes de funcionar bem em conjunto não significa que a identidade étnica era o principal tipo de organização coletiva na Itália pré-romana. A etnia era um entre vários tipos de organização e identificação coletiva, junto com a cidade, a aldeia, a classe e a família, entre outros. É justamente a dinâmica entre esses diferentes "níveis" de agrupamento, e sua mudança através do tempo, que constitui um objeto de estudo intrigante.

${ }^{38}$ Estrabão 5.3.1, 5.4.12, 61.6; Festus, p. 436 Lindsay; Varrão, de Lingua Latina, 7.29.1-7; Aulus Gellius 11.1.5; Apiano, Samn., 4.5; Paulo Diácono, p. 437 Lindsay.

${ }^{39}$ Estrabão 5.4.12; Salmon (1967, p. 167, n. 6).

40 Estrabão 5.4.2; Plínio, História natural, 3.110; Dench (1995, p. 185).

${ }^{41}$ Ovídio, Fasti, 3.95-6. 
Houve um momento em que muitos povos da Itália começaram a pensar a si próprios como "italianos". Em certa medida, a ideia de identidade italiana surgiu e desenvolveu-se em relação à conquista romana da península. A consolidação da hegemonia romana no Mediterrâneo, no início do século II a.C., significou que os aliados italianos de Roma podiam, a partir daquele momento, participar diretamente das redes globais de comércio que atravessavam o mundo helenístico. A presença de mercadores italianos trabalhando juntos em centros comerciais como o porto livre de Delos (fundado em 166 a.C.) tornou possível uma tomada de consciência pan-italiana. $\mathrm{O}$ fato de que comerciantes italianos de diferentes partes da península se viram obrigados a cooperar uns com os outros em Delos, sob as mesmas leis e regulamentos, certamente teve uma influência no processo pelo qual essas pessoas começaram a identificar-se como "italianos" (Italikoi) nas inscrições, e não como "samnitas", "campanos" ou "latinos" (Hatzfeld, 1912, p. 5-218; Rosellar, 2012, p. 141-158). Esse fenômeno não foi muito diferente do que ocorrera séculos antes entre os comerciantes gregos no empório de Náucratis, no Egito (Malkin, 2011, p. 93). Lá, comerciantes de diversas poleis e regiões da Grécia eram tratados como um grupo homogêneo pela população egípcia local. Da mesma forma, os comerciantes em Delos, provenientes de diferentes cidades e regiões da Itália, eram vistos como um grupo coeso pelos gregos, de modo que os "italianos" vieram a adotar essa imagem unificada para si próprios.

Essa noção mais ampla de "Itália" e "italianos" tornou-se o grito de guerra dos insurgentes durante a Guerra Social de 91-87 a.C., quando vários aliados italianos de Roma declararam guerra à cidade, movidos por uma série de frustrações e descontentamentos (Pobjoy, 2000, 187-211). Ao final da guerra, depois que os italianos tinham recebido a cidadania romana (o que havia sido, possivelmente, uma de suas reivindicações iniciais), as velhas "bandeiras" étnicas, que tinham sido tão importantes nos séculos precedentes, teriam perdido sua relevância. Contudo, as fontes historiográficas nos sugerem que os antigos nomes étnicos sobreviveram durante o período imperial. Por exemplo, Tácito menciona "samnitas", "marsos" e paelignos" entre os grupos que apoiaram o imperador Vespasiano durante a crise de sucessão de 69 a.D. ${ }^{42}$ Em que sentido as velhas identidades étnicas continuaram tendo significado nessa fase mais tardia da história da Itália, e até que ponto elas estavam relacionadas com os velhos ethne e populi do período republicano, são questões que permanecem a ser exploradas.

42 Tácito, Histórias, 3.59 


\section{Referências bibliográficas}

ADAMS, James. Bilingualism and the latin language. Cambridge: Cambridge University Press, 2003. ALTAN, Carlo Tullio. Ethnos e civiltà: identità etniche e valori democratici. Milão: Feltrinelli, 1995. AMPOLO, Carmine. Demarato, osservazioni sulla mobilità sociale arcaica. Dialoghi di Archeologia, Milão, v. 9-10, p. 333-345, 1976-1977.

ASSMAN, Jan. Cultural memory and early civilization: writing, remembrance, and political imagination. Cambridge: Cambridge University Press, 2011.

ASTON, Emma. Friends in high places: the stereotype of dangerous thessalian hospitality in the later classical period. Phoenix, Toronto, v. 66, fasc. 3-4, p. 247-271, 2012.

BARTH, Fredrik. Introduction. In:

(Org.). Ethnic groups and boundaries: the social organization of culture difference. Boston: Little, Brown and Co., 1969.

BENTLEY, G. Carter. Ethnicity and practice. Comparative Studies in Society and History, Cambridge, v. 29, fasc. 1, p. 24-55, 1987.

BISPHAM, Edward; BRADLEY, Guy; HAWTHORNE, W. J.; KANE, Susan. Towards a phenomenology of Samnite fortified centres. Antiquity: a quarterly review of world archaeology. Durham: Department of Archaeology, University of Durham 2000. v. 74.

BLAKE, Emma. Social networks, path dependence, and the rise of ethnic groups in pre-Roman Italy. In: KNAPPETT, Karl (Org.). Network analysis in archaeology: new approaches to regional interaction. Oxford: Oxford University Press, 2011.

BOURDIEU, Pierre. Outline of a theory of practice. Cambridge: Cambridge University Press, 1977. BOURDIN, Stéphane. Les peuples de l'Italie préromaine: identités, territoires et relations inter-ethniques en Italie centrale et septentrionale (VIIIe-1er s. av. J.-C.). Roma: Ecole Française de Rome, 2012.

BRADLEY, Guy. Ancient Umbria: state, culture and identity in central Italy from the Iron Age to the Augustan Era. Oxford: Oxford University Press, 2000a.

. States, cities, and tribes in central Italy. In: HERRING, Edward; LOMAS, Katherine (Org.).

The emergence of state identities in Italy. Londres: Accordia Research Institute, 2000b.

BUCKLER, John; BECK, Hans. Central Greece and the politics of power in the fourth century BC. Cambridge: Cambridge University Press, 2008.

CORNELL, Timothy. Ethnicity as a factor in early Roman history. In: ; LOMAS, Katherine

(Org.). Gender and ethnicity in ancient Italy. Londres: Accordia Research Institute, 1997.

. The beginnings of Rome. Londres: Routledge, 1995.

DENCH, Emma. From barbarians to new men: greek, roman and modern perceptions of the Central Appenines. Oxford: Clarendon, 1995.

. Romulus' asylum: Roman identities from the age of Alexander to the age of Hadrian.

Oxford: Oxford University Press, 2005.

DERKS, Ton; ROYMANS, Nico (Org.). Ethnic constructs in antiquity. Amsterdã: University of Amsterdam Press, 2009.

ECKSTEIN, Arthur. Mediterranean anarchy, interstate war, and the rise of Rome. Berkeley: University of California Press, 2006.

ERIKSEN, Thomas H. Ethnicity and nationalism: anthropological perspectives. Londres: Pluto, 1993. FARNEY, Gary. Ethnic identity and aristocratic competition in republican Rome. Cambridge: Cambridge University Press, 2007.

GLINISTER, Fay. Reconsidering “religious romanization”. In: SCHULTZ, Celia E.; HARVEY, Paul B. (Org.). Religion in republican Italy. Cambridge: Cambridge University Press, 2006.

GRANINGER, Denver. Cult and koinon in hellenistic Thessaly. Leiden: Brill, 2011.

HALL, Jonathan. Ethnic identity in greek antiquity. Cambridge: Cambridge University Press, 1997. . Hellenicity: between ethnicity and culture. Chicago, University of Chicago Press, 2002.

. Polis, community and ethnic identity. In: SHAPIRO, H. A. (Org.). The Cambridge companion to archaic Greece. Cambridge: Cambridge University Press, 2006.

HANSEN, Mogens; NIELSEN, Thomas. An inventory of archaic and classical poleis. Oxford: Oxford University Press, 2004.

HATZFELD, Jean. Les italiens résidant à Délos mentionnés dans les inscriptions de l'île. Bulletin de Correspondance Hellénique, Atenas, v. 36, fasc.1, p. 5-218, 1912.

HERRING, Edward; LOMAS, Katherine (Org.). The emergence of state identities in Italy in the first millennium BC. Londres: Accordia Research Institute, 2000. 
ISAYEV, Elena. Inside ancient Lucania: dialogues in history and archaeology. Bulletin of the Institute of Classical Studies, Londres: Institute of Classical Studies, supl. 90, p. 24-25, 2007.

. Migration, mobility and place: relational paradigms from ancient Italy. No prelo.

JONES, Sian. The archaeology of ethnicity: constructing identities in the past and present. Londres: Routledge, 1997.

KEYSER, P. T. Greek geography of the western barbarians. In: BONFANTE, Larissa (Org.). The barbarians of ancient Europe: realities and interactions. Cambridge: Cambridge University Press, 2011.

LA REGINA, Adriano. Appunti su entità etniche e strutture istituzionali nel Sannio antico. Annali dell'Istituto Orientale di Napoli, Archeologia e Storia Antica, Nápoles: Istituto Universitario 'L'Orentale', v. 3, 1981.

. Il Sannio. In: ZANKER, Paul (Org.). Hellenismus in Mittelitalien. Kolloquium in Göttingen vom 5. bis 9. Juni 1974. Göttingen: Vanderhoeck und Ruprecht, 1976.

LOMAS, Katherine. Cities, states and ethnic identity in southeast Italy. In: HERRING, Edward; LOMAS, Katherine (Org.). The emergence of state identities in Italy in the first millennium BC. Londres: Accordia Research Institute, 2000.

LURAGHI, Nino. The ancient messenians: constructions of ethnicity and memory. Cambridge: Cambridge University Press, 2008.

MALKIN, Irad (Org.). Ancient perceptions of greek ethicity. Washington D.C.: Center for Hellenic Studies/Trustees for Harvard University, 2001.

Press, 2011.

A small greek world: networks in the ancient Mediterranean. Oxford: Oxford University

MORGAN, Catherine. Early greek states beyond the polis. Londres: Routledge, 2003.

Politics without the polis: cities and the Achaean ethnos, c. 800-500 BC. In: BROCK, Roger; HODKINSON, Stephen (Org.). Alternatives to Athens: varieties of political organization and community in ancient Greece. Oxford: Oxford University Press, 2000.

OAKLEY, Stephen. A commentary on Livy, books VI-X. Oxford: Oxford University Press, 19972005. v. I-II.

PATTERSON, Orlando. Context and choice in ethnic allegiance: a theoretical framework and caribbean case study. In: GLAZER, Nathan; MOYNIHAN, Daniel (Org.). Ethnicity: theory and experience. Cambridge, MA: Harvard University Press, 1975.

POBJOY, Mark. The first Italia. In: HERRING, Edward; LOMAS, Katherine (Org.). The emergence of state identities in Italy in the first millennium B.C. Londres: Accordia Research Institute, 2000. RAAFLAUB, Kurt. Philosophy, science, politics: Herodotus and the intellectual trends of his time. In: BAKKER, Evert Jan; JONG, Irene J. F. de; VAN WEES, Hans (Org.). Brill's companion to Herodotus. Leiden: Brill, 2002.

ROSELLAR, Saskia T. Mediterranean trade as a process of integration between romans and italians. In: ROSELLAR, Saskia T. (Org.). Processes of integration and identity formation in the roman republic. Leiden: Brill, 2012.

RUTTER, N. Keith (Org.). Historia numorum: Italy. Londres: British Museum Press, 2001.

SALMON, Edward Togo. Samnium and the samnites. Cambridge: Cambridge University Press, 1967. SCOPACASA, Rafael. Ancient Samnium: settlement, culture and identity between history and archaeology. Oxford: Oxford University Press. No prelo. . Building communities in ancient Samnium: cult, ethnicity and nested identities. Oxford Journal of Archaeology, Oxford, v. 33, fasc. 1, p. 69-87, 2014.

. Essere sannita: rappresentazioni d'un popolo italico nelle fonti letterarie e storiografiche antiche. Campobasso: Istituto Regionale per gli Studi Storici del Molise "V. Cuoco", 2007. SHENNAN, Stephen. Archaeological approaches to cultural identity. Londres: Routledge, 1994. SMITH, Anthony D. The ethnic origins of nations. Oxford: Blackwell, 1986.

TAGLIAMONTE, Gianluca. I Sanniti. Milão: Longanesi, 1996.

STEK, Tesse. Cult places and cultural change in republican Italy: a contextual approach to religious aspects of rural society after the Roman conquest. Amsterdã: Amsterdam University Press, 2009. WALLACE-HADRILL, Andrew. Rome's cultural revolution. Cambridge: Cambridge University Press, 2008.

WEBER, Max. Economy and society: an outline of interpretive sociology. Nova York: Bedminster, 1968. v. 1.

YNTEMA, Douwe. Material culture and plural identity in early Roman southern Italy. In: DERKS, Ton; ROYMANS, Nico (Org.). Ethnic constructs in Antiquity. Amsterdã: Amsterdam University Press, 2009. 